\title{
Initial experience with extracorporeal membrane oxygenation following cardiac surgery in children with congenital heart disease
}

\author{
Apurb Sharma ${ }^{1}$, Jeju Nath Pokharel ${ }^{1}$, Murari Raj Upreti ${ }^{1}$, Bhagawan Koirala ${ }^{2}$, \\ Jyotindra Sharma ${ }^{3}$, Siddartha Pradhan ${ }^{3}$, Mahendra Bhatta ${ }^{2}$ \\ ${ }^{1}$ Department of Anaethesiology,Shahid Gangalal National Heart Centre, Bansbari, Kathmandu, Nepal. \\ ${ }^{2}$ Manmohan Cardiothoracic Vascular and Transplant Centre, Institute of Medicine, Maharajgunj, Kathmandu, Nepal. \\ ${ }^{3}$ Department of Cardiac Surgery, Shahid Gangalal National Heart Centre, Bansbari, Kathmandu, Nepal.
}

\section{Citation \\ Apurb Sharma, Jeju Nath Pokharel, Murari Raj Upreti, et al. Initial experience with extracorporeal membrane oxygenation following cardiac surgery in children with congenital heart disease. Nepalese Heart Journal 2014;11(1): 39-44.}

\section{Keywords}

congenital heart defects, Extracorporeal Membrane Oxygenation, cardiac surgical procedures

\section{INTRODUCTION}

Extra-corporeal membrane oxygenation (ECMO) for postoperative support has become an invaluable tool in the management of patients at a majority of centers performing pediatric cardiac surgery. ${ }^{1}$ In the western world, the first application of ECMO following repair of congenital heart disease in a pediatric patient was done in $1970 .{ }^{2}$ Around

\begin{abstract}
S
Background and Aim: Cardiac extra-corporeal membrane oxygenation is a mechanical life support system initiated in patients with extreme cardiopulmonary failure. Extracorporeal circulation after cardiac surgery supports the heart and lungs recover from the acute injuries of the surgery. Aims of this study were to present our initial experience about complications and outcome with the use of extracorporeal membrane oxygenation following open-heart surgery for congenital cardiac anomalies.
\end{abstract}

Methods: Medical records of all pediatric and neonatal patients requiring extracorporeal life support following cardiac surgery for congenital cardiac anomalies were retrospectively reviewed. Patient and extracorporeal system characteristics were evaluated.

Results: Between 2009 and 2012, eight children were treated at our institution with mechanical extracorporeal life support system following open heart surgery. Median age was four months and mean weight was 7.24 kilograms. The indications for initiation of extracorporeal support were difficulty in weaning off cardiopulmonary bypass despite maximal inotropic support, refractory pulmonary oedema immediately after cardiopulmonary bypass and right ventricular dysfunction in postoperative period. Two patients were weaned from the extracorporeal support successfully.

Conclusions: Initial results of our extra-corporeal membrane oxygenation programme do not meet the international standards. It can still be a valuable strategy for saving lives after paediatric cardiac surgery.

\section{Corresponding author}

Apurb Sharma

Department of Anaesthesiology, Shahid Gangalal National Heart Centre, Bansbari, Kathmandu, Nepal.

Email: apurbsharma1976@gmail.com 
the world, the number of children treated by ECMO has increased gradually over the past decade. ${ }^{1,3,4}$ This study intended to evaluate the demographic profile, clinical variables, technical considerations and clinical outcome of children in whom ECMO was used after repair of congenital cardiac anomalies and to report the initial experience after starting an ECMO programme in a tertiary cardiac centre.

\section{METHODS}

After approval from the institutional review board, we retrospectively reviewed the medical records (hospital admission records, operative reports, perfusion data, and pediatric intensive care unit sheets) to collect the demographic information, clinical variables, technical details and clinical outcome of the patients supported with ECMO after cardiac surgery from October 2009 to September 2012.

\section{ECMO circuit design}

The ECMO circuit consisted of a venous cannula draining the blood to a centrifugal blood pump (Bio-Pump BP-50; Medtronic, Inc, Minneapolis, MN, USA) in conjunction with an oxygenator (ECMO 0800, membrane oxygenator, Medtronic, Inc, Minneapolis, MN, USA). The oxygenated blood from the oxygenator was returned to the patient through an arterial cannula. The system was operated by ECMO machine (Bio console-560, Medtronic, Inc, Minneapolis, MN, USA). There was a connecting bridge between arterial and venous line of the ECMO circuit. All components were heparin coated. Temperature of the patient was regulated by temperature controller (Bio Cal ( ) 370I, Cardiopulmonary bypass temperature controller, Medtronic, Inc, Minneapolis, MN, USA).

\section{Patient management during ECMO support}

The patients were heparinized to attain an activated clotting time of 180 to 250 seconds. The goal was to provide a systemic oxygenated blood flow of average 2.4litres/ minute/metre ${ }^{2}$ as full circulatory support. The patients were not cooled during ECMO mechanical circulatory support.
Inotropes and vasopressors were used to maintain mean arterial pressure of 40 to $60 \mathrm{mmHg}$. Echocardiography was performed everyday to determine whether the left ventricle was distended and whether decompression was necessary or to determine if any potentially correctable cardiac defects were present. Ventilator settings were generally set to a rate of 16 breaths per minute, positive end-expiratory pressure of five, $\mathrm{FiO}_{2}$ of $40 \%$ and tidal volume of eight $\mathrm{mL} / \mathrm{Kg}$. All patients on mechanical support were given neuromuscular blocking agents and heavily sedated with benzodiazepine and narcotics. Alpha stat blood gas management was employed routinely. When there was evidence of multi organ failure, severe sepsis or profound neurological impact, termination of ECMO was considered. Successful separation from ECMO support was determined by transient reduction in ECMO flows with echocardiographic guidance to assess ventricular filling and function. Once ventilatory and inotropic support was increased according to the patient's needs, flows were gradually decreased. When indicated, the arterial and venous lines were clamped while full anticoagulation was maintained to allow a temporary period for hemodynamic assessment. Decannulation of aortic and venous cannula was considered when patient was haemodynamically stable for 15 to 20 minutes.

Data was analyzed with the SPSS 12.0 for Windows software program (SPSS, Chicago, IL, USA). Demographic variables are expressed as absolute values and continuous data as mean \pm standard deviation (SD) when they were approximately normally distributed but as medians and ranges when they were not. Variables observed included age, weight, sex, duration of CPB during surgery, duration of aortic cross clamp, duration of ECMO support, surgical site bleeding, creatinine $>1.5 \mathrm{mg} / \mathrm{dl}$, need for renal replacement therapy (RRT), pneumothorax, inotrope requirement on ECMO, cardiac arrhythmia, culture proven new infection, acidosis with $\mathrm{pH}<7.2$, transfusion requirement on ECMO. 


\section{RESULTS}

During the three year study period eight infants and children were supported on ECMO. The patient characteristics, the mean cardiopulmonary bypass time (CPB) and the mean aortic cross-clamp time are shown in table 1. ECMO support was indicated due to difficulty in weaning from $\mathrm{CPB}$ despite maximal inotropic support in three patients, refractory pulmonary oedema immediately after CPB in two patients and right ventricular failure with low cardiac output in the post-CPB period in three patients. Extracorporeal support was initiated in the operating room in seven patients and in the intensive care unit in one patient.
Table 1. Patient Characteristics

\begin{tabular}{|c|c|}
\hline Variable & \\
\hline Sex (male/female) & $3 / 5$ \\
\hline Median age (range) in months & $4(2$ to 120$)$ \\
\hline Height in cm (mean \pm SD) & $73 \pm 26.88$ \\
\hline Weight in Kg (mean \pm SD) & $7.37 \pm 7.89$ \\
\hline CPB time (mean \pm SD) & $239.25 \pm 81.42$ \\
\hline $\begin{array}{c}\text { Aortic Cross clamp time }(\text { AoX) } \\
(\text { mean } \pm \text { SD) }\end{array}$ & $99 \pm 29.76$ \\
\hline
\end{tabular}

The diagnoses, operative procedure, duration of ECMO support and outcome are shown in table 2.

Table 2 : Diagnosis, Procedure, Duration of ECMO support and outcome

\begin{tabular}{|c|c|c|c|c|c|}
\hline Diagnosis & $\begin{array}{c}\text { Age } \\
\text { (month) }\end{array}$ & Surgery & $\begin{array}{l}\text { Days on } \\
\text { ECMO }\end{array}$ & $\begin{array}{l}\text { ECMO } \\
\text { Weaned }\end{array}$ & $\begin{array}{l}\text { Weaned off } \\
\text { Ventilator }\end{array}$ \\
\hline TAPVC & 2 & Re-routing of TAPVC & 7 & No & - \\
\hline $\begin{array}{c}\text { D-TGA VSD } \\
\text { PAH }\end{array}$ & 4 & Arterial Switch VSD closure & 2 & No & - \\
\hline TAPVC PDA & 4 & Re-routing PDA ligation & 3 & Yes & No \\
\hline D-TGA PDA & 2 & Arterial Switch & 5 & No & - \\
\hline $\begin{array}{l}\text { Truncus } \\
\text { Arteriosus }\end{array}$ & 2 & RV-PA conduit Truncal Valve repair & 2 & No & - \\
\hline VSD PAH MR & 8 & VSD closure MV repair & 6 & Yes & Yes \\
\hline $\begin{array}{c}\text { TOF post central } \\
\text { shunt }\end{array}$ & 60 & Intracardiac Repair & 5 & No & - \\
\hline DORV PS & 120 & Intracardiac repair & 6 & No & - \\
\hline
\end{tabular}

TAPVC - Total Anomalous Pulmonary Venous Connection, D-TGA - D-Transposition of Great Arteries, VSD - Ventricular Septal Defect, PAH - Pulmonary Artery Hypertension, MR - Mitral Regurgitation, TOF- Tetralogy of Fallot, DORV Double Outlet Right Ventricle, PS - Pulmonic Stenosis

Two patients with Total Anomalous Pulmonary Venous Connection (TAPVC) and a patient with Truncus Arteriosus required ECMO support for pulmonary oedema refractory to conventional medical management while being weaned from CPB. The patients who underwent arterial switch operation and the patient after closure of ventricular septal defect (VSD) with repair 
of mitral valve (MV) required ECMO because of difficulty in weaning from CPB despite maximal inotropic support. Patients with Double outlet right ventricle (DORV) with pulmonic stenosis (PS) and Tetralogy of Fallot (TOF) had undergone intracardiac repair via trans-atrial transpulmonary approach. They required extracorporeal support for post-operative right ventricular failure.

The mean duration of extracorporeal support was $4.50 \pm 1.92$ days. Extracorporeal support was successfully weaned in two patients and one of them was weaned off ventilator. The causes of death were related to cardiogenic shock and multiorgan dysfunction, bleeding due to coagulation abnormalities causing decreased venous return on ECMO circuit and renal impairment in majority of the cases. The complications associated with extracorporeal life support are shown in Table 3. Renal replacement therapy (RRT) with the use of peritoneal dialysis was considered in six patients.

Table 3. Complications Associated with ECMO

\section{Parameter observed}

\begin{tabular}{|l|l|}
\hline Inotrope Requirement on ECMO & 8 \\
\hline Creatinine $>1.5 \mathrm{mg} / \mathrm{dL}$ & 7 \\
\hline Need for RRT (peritoneal dialysis) & 6 \\
\hline $\begin{array}{l}\text { Surgical site bleeding requiring re- } \\
\text { exploration }\end{array}$ & 5 \\
\hline Cardiac Arrhythmia & 3 \\
\hline Metabolic acidosis $(\mathrm{pH}<7.2)$ & 2 \\
\hline Pneumothorax & 2 \\
\hline
\end{tabular}

\section{DISCUSSION}

Extracorporeal life support with centrifugal pump and membrane oxygenator has been used with satisfactory results in cardiac centers for many years. ${ }^{1,5,6}$ It is an effective method to achieve control over severe hemodynamic instability or respiratory alterations in the post-operative period after cardiovascular surgery. ${ }^{7.8}$ It also allows the recovery of target-organs or as bridge for ventricular assist device (VAD) and transplant in selected cases. ${ }^{9,10,11}$

In this study, ECMO was restricted to a pediatric population, with six of eight patients being infants and all the patients had biventricular heart. Extracorporeal support was successfully weaned from two out of eight patients and one patient was successfully weaned off ventilator. ECMO is a treatment modality that has a high complication rate and mortality. However the mortality associated with ECMO is less than that of conventional medical therapy. So ECMO should be considered in those patients who are likely to benefit from it.

The mortality observed in our study population is higher than that of international reported data ${ }^{12}$, which includes registered centers that send their data voluntarily. Those data ${ }^{12}$ includes initiation of ECMO for respiratory indications too. Recent international registry data survival rates for pediatric patients placed on ECMO for respiratory and cardiac indications are $64 \%$ and $62 \%$, respectively. ${ }^{13}$ The outcome of patients placed on ECMO varies according to the center, reflecting several types of indication and adverse factors related to the patient. Clinicians at the University of Michigan have suggested that an institution must treat a minimum of 10 to 20 patients to demonstrate consistent reproducible management strategies and outcomes for ECMO recipients. ${ }^{14}$ The results of our ECMO population should improve with further exposure and experience.

Alsoufi et al identified age, weight, type and duration of assistance, univentricular physiology, re-exploration, number of complications, sepsis, renal and respiratory failure as mortality risk factors for patients placed on extracorporeal support after paediatric cardiac surgery. ${ }^{15}$ Similarly, Balasubhramanian et al $^{16}$ evaluated factors influencing outcome of paediatric cardiac surgical patients on extracorporeal support and found that abnormal neurology, bleeding complications on ECMO and arrhythmias are prognostically poor indicators of outcome. Inotrope requirement on ECMO is another poor predictor ${ }^{17}$ and all of our patients required high doses of inotropes and vasopressors during extracorporeal support. Similarly, cardiac arrhythmias, renal failure, bleeding from mediastinal cannulation site were other factors that might have contributed to poor outcome of our patients.

The majority of patients in our institution were placed on ECMO in the operating room. The mechanical support was maintained via the original bypass cannulae and converted to a closed ECMO system. Early initiation of ECMO is the key to survival. ${ }^{18}$ Similarly, delayed commencement of ECMO leads to unsatisfactory outcomes. ${ }^{19}$ Our ECMO patients must have benefited in this aspect but was not reflected in the results. 
With the initiation of $\mathrm{CPB}$, widespread activation of the haemostatic system occurs. This involves the coagulation system, endothelium and regulatory proteins, platelets, and fibrinolysis. This can result in micro thrombi generation during $\mathrm{CPB}$, coagulation defects after its termination, and even hypercoagulability leading to thrombotic complications in the postoperative period. ${ }^{20}$ A significant inflammatory response and subsequent organ dysfunction is known to be associated with the use of CPB and almost all patients treated with ECMO develop systemic inflammatory response syndrome characterized by cytokine release, leukocyte activation and multisystem organ dysfunction. ${ }^{21}$ Most of our ECMO patients developed multiorgan dysfunction and had to be on high inotropic support, developed bleeding complications, metabolic acidosis and renal insufficiency that required renal replacement therapy.
Early identification of patients that may benefit from the extracorporeal support and prompt initiation of ECMO, early recognition of complications and development of multidisciplinary approach should lead to a better outcome in future. The small number of study population and its retrospective nature are the limitations of the study.

In conclusion, initial results of our extracorporeal life support programme, with its high complication rate, does not meet the established international standards but it can still be a valuable tool for saving lives of many critical patients. Development of experienced multi-professional team, identification of selection criteria, early recognition and treatment of complications should lead to improved survival.

support after cardiac surgery. Ann Thorac Surg 2003;76:1435-42. http://dx.doi.org/10.1016/S00034975(03)00898-1

6 Undar A, McKenzie ED, McGarry MC, Owens WR, Surprise DL, Kilpack VD, et al: Outcomes of congenital heart surgery patients after extracorporeal life support at Texas Children's Hospital. Artif Organs 2004;28:963-6. http:// dx.doi.org/10.1111/j.1525-1594.2004.07378.x

7 Walters HL, Hakimi M, Rice MD, Lyons JM, Whittlesey GC, Klein MD: Pediatric cardiac surgical ECMO: multivariate analysis of risk factors for hospital death. Ann Thorac Surg 1995;60:329-36. http://dx.doi.org/10.1016/00034975(95)00410-M

8 Dhillon R, Pearson GA, Firmin RK, Chan $\mathrm{KC}$, Leanage R: Extracorporeal membrane oxygenation and the treatment of critical pulmonary hypertension in congenital heart disease. Eur J Cardiothorac Surg. 1995;9:553-6. http://dx.doi.org/10.1016/S1010-7940(05)80004-1

9 Duncan BW, Bohn DJ, Atz AM, French JW, Laussen PC, Wessel DL: Mechanical circulatory support for the treatment of children with acute fulminant myocarditis. J Thorac Cardiovasc 
Surg 2001;122:440-8. http://dx.doi.org/10.1067/ mtc. 2001.115243

10 Gajarski RJ, Mosca RS, Ohye RG, Bove EL, Crowley DC, Custer JR, et al: Use of extracorporeal life support as a bridge to pediatric cardiac transplantation. J Heart Lung Transplant 2003;22:28-34. http://dx.doi.org/10.1016/S10532498(02)00476-X

11 Fiser WP, Yetman AT, Gunselman RJ, Fasules JW, Baker LL, Chipman CW, et al: Pediatric arteriovenous extracorporeal membrane oxygenation (ECMO) as a bridge to cardiac transplantation. J Heart Lung Transplant 2003;22:770-7. http://dx.doi.org/10.1016/S10532498(02)00808-2

12 Meliones JN, Custer JR, Snedecor S, Moler FW, O'Rourke PP, Delius RE: Extracorporeal life support for cardiac assist in pediatric patients: review of ELSO Registry data. Circulation 1991;84(5):168-72.

13 Crow S, Fischer AC, Schears RM: Extracorporeal life support: utilization, cost, controversy, and ethics of trying to save lives. Semin Cardiothorac Vasc Anesth 2009;13:183-91. http://dx.doi. org/10.1177/1089253209347385

14 Hemmila MR, Rowe SA, Boules TN, Miskulin J, McGillicuddy JW, Schuerer DJ, et al:

Extracorporeal life support for severe acute respiratory distress syndrome in adults. Ann Surg 2004;240:595-607.

15 Alsoufi B, Shen I, Karamlou T, Giacomuzzi C, Burch G, Silberbach M, et al: Extracorporeal life support in neonates, infants, and children after repair of congenital heart disease: modern era results in a single institution. Ann Thorac Surg. 2005; 80: 15-21. http://dx.doi.org/10.1016/j. athoracsur.2005.02.023

16 Balasubramanian SK, Tiruvoipati R, Amin M, Aabideen KK, Peek GJ, Sosnowski AW et al: Factors influencing the outcome of paediatric cardiac surgical patients during extracorporeal circulatory support. Journal of Cardiothoracic Surgery 2007;11:2-4.

17 Baslaim G, Bashore J, Al-Malki F, Jamjoom A: Can the outcome of pediatric extracorporeal membrane oxygenation after cardiac surgery be predicted? Ann Thorac Cardiovasc surg. 2006;12:21-7.

18 Chauhan S, Malik M, Malik V, Chauhan Y, Kiran U, Bisoi AK. Extra corporeal membrane oxygenation after pediatric cardiac surgery: a 10 year experience. Ann Card Anaesth 2011;14:19-24.

19 Chakravarthy M. ECMO - the way to go. Ann Card Anaesth 2011;14:1-2.

20 Sniecinski RM, Chandler WL. Activation of the Hemostatic System During Cardiopulmonary Bypass. Anesth Analg 2011;113:1319-33. http:// dx.doi.org/10.1213/ANE.0b013e3182354b7e

21 McILwain RB, Timpa JG, Kurundkar AR, Holt DW, Kelly DR, Hartman YE, et al. Plasma concentrations of inflammatory cytokines rise rapidly during ECMO-related SIRS due to the release of preformed stores in the intestine. Lab Invest 2010;90:128-39. http://dx.doi.org/10.1038/ labinvest.2009.119 